\title{
Evaluation of Regenerative Periodontal Therapy in Intrabony Defects with Single Flap Approach Using Bovine Xenograft in Smokers and Non-smokers
}

\section{Dalli Bharath Simha Reddy ${ }^{1}$, Rupasree Gundala ${ }^{2 *}$, Kankipati Amrutha ${ }^{1}$, Nemakal Sumana ${ }^{1}$, Ch Susmitha SS ${ }^{1}$ and Sravani Bontu ${ }^{1}$}

${ }^{1}$ Postgraduate Student, Department of Periodontics,Lenora Institute of Dental Sciences,

Rajamahendravaram, India

${ }^{2}$ Assistant Professor, Government Dental College and Hospital, Vijayawada, India

*Corresponding Author: Dalli Bharath Simha Reddy, Postgraduate Student, Department of Periodontics, Lenora Institute of Dental Sciences, Rajamahendravaram, India.
Received: February 19, 2021

Published: March 11, 2021

(C) All rights are reserved by Dalli Bharath

Simha Reddy., et al.

\section{Abstract}

Introduction: Periodontal disease is the most prevalent disease across the world. It is an inflammatory disease involving progressive and episodic loss of the periodontal attachment apparatus with tissue destruction consequentially arising out of host response against bacterial antigens as well as irritants leads to loss of alveolar bone and supporting the teeth. Chronic periodontitis causes various types of bony defects, among them intra-bony defect is most common. There are two primary treatment modalities for treating periodontitis and associated changes, including non-surgical and surgical periodontal therapy.

Aims and Objectives: To compare the results yielded by bovine xenograft in smokers and nonsmokers patients with chronic periodontitis from baseline to 6 months. To compare the clinical parameters - probing depth (PD), clinical Attachment Level (CAL), radiographic Bone fill from baseline to 6 months after the surgical therapy.

Materials and Methods: A cross-sectional clinical study was conducted with a sample of twenty-four patients selected from department of periodontics, Lenora institute of dental sciences, Rajahmundry, Andhra Pradesh, India. The patients selected for this study are divided in to two groups i.e., Smokers group and Non-smokers' group. Initially both Smokers and Non-smokers sites were treated with scaling and root planing alone. Patients included in this study were treated with bovine xenograft using single flap approach technique.

Results: All values were subjected for statistical analysis by using the following formulas Unpaired ' $t$ ' Test or independent sample ' $t$ ' test, Paired " $\mathrm{t}$ ” test, Mann-Whitney U test.

Conclusion: We found that there was significant improvement in clinical parameters i.e., plaque index (PLI), sulcus bleeding index (SBI), probing depth (PD), clinical attachment level (CAL), and bone fill in the sites, before and after periodontal treatment. There was a significant improvement in clinical attachment level gain and bone fill in both the groups treated with bovine xenograft using a single flap approach from baseline to six months. The results of this study point towards the novel direction of current surgical regenerative approaches. Further, long term, multi-center, prospective longitudinal trials are the need of the hour to confirm the find-ing of this study.

Keywords: Probing Depth (PD); Clinical Attachment Level (CAL); Smoker 


\section{Introduction}

Periodontal disease is the most prevalent disease across the world. It is an inflammatory disease involving progressive and episodic loss of the periodontal attachment apparatus with tissue destruction consequentially arising out of host response against bacterial antigens as well as irritants leads to loss of alveolar bone and supporting the teeth. Chronic periodontitis causes various types of bony defects, among them intrabony defect is most common [1,2].

Intrabony defects, can also be recognized as site specific risk factor for periodontal disease progression, leading to non-resolving pockets with continued debris accumulation and serves as a niche for bacterial colonization, which can lead to premature tooth loss if left untreated. There are two primary treatment modalities for treating periodontitis and associated changes, including nonsurgical and surgical periodontal therapy.

For regeneration of lost tissues, surgical periodontal treatment has been one of the most favored approaches in treating chronic periodontitis affected tooth, manifesting intrabony defects [3]. The selection of a regenerative approach is generally based on the intrabony defect site features, including bony defect morphology, root surface topography and gingival biotype. Three-wall intrabony defects, mainly which are narrow as well as deep seem to offer a spatial configuration with the most significant inherent potential for periodontal regeneration.

Regenerative periodontal therapy intention is the rejuvenation of the lost tooth supporting structures. There are several treatment procedures for regenerative periodontal therapy, including open flap debridement with or without bone substitutes, and guided tissue regeneration.

Innumerable regenerative materials such as autogenous, allogenous, xenogenous, and alloplastic graft materials have been used. For most favorable results, an epitome bone graft should have the chattels of osteoproliferation, osteoinduction, and osteoconduction at dissimilar time periods after placement. Autogenous bone grafts has been deemed gold standard as it has all three properties. Nevertheless, the risk of infection at the donor site and limited availability restricts its use. To overcome these complications, different bone substitutes are experimented $[4,5]$.

Periodontitis can be treated with periodontal flap surgery; Flap provides access to underlying tissues and permits the surgeon to perform a variety of regenerative procedures [6]. The most collective postoperative difficulty is associated with traditional flap approach for grafting techniques is immediate, partial or complete exfoliation of the graft materials. It most often due to surgical procedure which results in incomplete tissue coverage of the graft material in the interproximal areas [7]. The tissue contraction concomitant with wound healing will often expose the graft material during the postoperative period. New surgical techniques have been established to optimize primary closure as well as to minimize the surgical trauma in the reconstructive procedures of intraosseous periodontal defects.

Papilla preservation technique was developed for use in conjunction with implants in periodontal osseous defects in 1994 by Takei HH, Han TJ [8]. Later In 1995 cortellini P [9], proposed a modification of the papilla preservation technique which has been applied to achieve primary cessation of the interproximal tissue over barrier membranes coronal to alveolar crest.

A minimal invasive procedure the single flap approach, specifically indicated when the defect extension is prevalent on the buccal or oral side. The basic Introduction principle of the single flap approach is the elevation of flap to access the defect only on one side (buccal or oral), leaving the opposite side intact. The purpose of developing new techniques is to increase predictability, reduce patient discomfort, minimize the number of surgical sites and satisfy aesthetic demands of the treatment.

Smoking has chronic effect with important inflammatory and immune responses. Smoking induces a significant systemic neutrophilia, but neutrophil transmigration across the periodontal micro vasculature is impeded. The suppression of neutrophil cell spreading, chemokinesis [10], chemotaxis and phagocytosis have been described.

Hence, in the present study, an attempt was made to assess the effect of bovine xenograft in smokers and non-smokers for the treatment of intrabony defects with single flap approach in patients with chronic periodontitis.

\section{Aims and Objectives}

To compare the results yielded by bovine xenograft in smokers and nonsmokers patients with chronic periodontitis from baseline to 6 months. 
To compare the clinical parameters.

- $\quad$ Probing depth (PD)

- Clinical Attachment Level (CAL)

- Radiographic Bone fill from baseline to 6 months after the surgical therapy.

\section{Materials and Methods}

A cross-sectional clinical study was conducted with a sample of twenty-four patients selected from department of periodontics, Lenora institute of dental sciences, Rajahmundry, Andhra Pradesh, India. The nature of the study was explained to all the participants and written informed consent was obtained. The patients selected for this study are divided in to two groups i.e., Smokers group and Non-smokers' group. Initially both Smokers and Non-smokers sites underwent scaling and root planing. Patients included in this study were treated with bovine xenograft using single flap approach technique.

\section{Study methods}

The selected patients were considered after a precise case history recording, that includes chief complaint, and clinical examination. Plaque index (PI), Sulcus bleeding index (SBI), Periodontal pocket depth (PPD), clinical attachment level (CAL), Early healing index after 2 weeks following the surgery, intrabony defect $\geq 5 \mathrm{~mm}$ (distance between alveolar crest and base of the defect as measured on an intraoral periapical radiograph ) were recorded in a proforma (appended) using a sterile mouth mirror and UNC 15 probe.

After recording all the clinical parameters in selected patients at baseline, thorough scaling and root planning was done using ultra sonic scalers and curettes. Surgical procedure was carried out after 3-4 weeks of initial periodontal therapy.

\section{Surgical procedure}

Intraoral antisepsis was done with $0.12 \%$ chlorhexidine digluconate rinse. Extra-oral antisepsis was done using iodine solution. Procedure was under done under local anesthesia (lidocaine 2\%); all surgeries were performed under using $2.5 x$ loupes. Before the surgery, trans-crevicular probing was performed to evaluate the extent of the defect. The surgical access was performed by the elevation of buccal muco-periosteal flap according to principle of buccal single flap approach.
Briefly, a sulcular incision was made following the gingiva margin of the teeth included in the surgical area, the mesiodistal extension of the flap kept limited, while ensuring access for defect debridement. An oblique or horizontal butt-joint incision was made at the level of the interdental papilla overlying the intraosseous defect. The greater the distance from the tip of the papilla to the underlying bone crest, the more apical (i.e., close to the base of the papilla) the buccal incision in the interdental area.

A buccal mucoperiosteal flap was elevated using a microsurgical periosteal elevator, the exposed root surfaces are rinsed with saline followed by placement of bovine xenograft bone material on the coronal portion of the exposed root surfaces (care was taken not to overfill the defect). The buccal flap was repositioned and sutured according to the single flap approach technique, consisting of horizontal internal mattress suture at the base of the papilla and a second internal mattress suture (vertical or horizontal) between the most coronal portion of the flap and the most coronal portion of oral papilla.

When necessary (e.g., in case of a large, thick interdental papilla), an interrupted suture was performed to ensure primary intention healing at the incision line. Periodontal dressing was given at site of the surgery, Suitable antibiotics and analgesics were prescribed, $0.12 \%$ chlorhexidine digluconate rinses is advised twice daily for two weeks, all the Patients were instructed to brush gently using soft tooth brush.

Post surgical procedure

Two weeks after the surgery, sutures were removed, Early Healing Index (EHI) was recorded at 2weeks following the surgery. All clinical parameters including plaque index, Sulcus bleeding index, Recession Depth, Periodontal Pocket Depth, Clinical attachment level and radiographic defect fill will be measured will be measured after six months post operatively.

\section{Inclusion criteria}

- Diagnosis of patient moderate or severe periodontitis

- $\quad$ Patients of age up to 45 years

- Presence of at least one interproximal periodontal intraosseous defect with pre-surgical probing depth $\geq 5 \mathrm{~mm}$

- No extension of periodontal intraosseous defect on the lingual or palatal side 
- Plaque index score and sulcus bleeding index score should be $<20 \%$ at the time of surgical procedure.

- Smokers included in this study are patients who smokes 1-10 cigarettes/day

- Compliance with the scheduled post-surgical recall sessions.

\section{Exclusion criteria}

- Using medication affecting periodontal status (eg: bisphosphonates, cyclosporin, phenytoin, nifedipine, and other calcium channel blockers)

- Furcation involvement of the tooth presenting intraosseous defect

- Patients with systemic diseases will be excluded

- Third molar teeth will be excluded

- For each smoking patient (i.e., a patient regularly smoking 1 cigarette per day despite motivation to quit.).

\section{Results}

All values were subjected for statistical analysis by using the following formulas Unpaired ' $t$ ' Test or independent sample ' $t$ ' test, Paired " $\mathrm{t}$ " test, Mann-Whitney U test.

The subjects for this study were obtained from the Department of Periodontology, Lenora Institute of Dental Sciences, Rajamahendravaram, Andhra Pradesh, india. Twenty-four patients were selected and divided into two Categories, smokers and nonsmokers.

Initially, scaling and root planing was done in all the sites. Both the categories are treated with bovine xenograft for the treatment of intra-bony defects with a single flap approach in patients with chronic periodontitis. Data were expressed as mean \pm SD. Withingroup comparisons (pre-surgery vs 6 months) were performed with Wilcoxon test. Intergroup comparisons were performed with Mann-Whitney U test. Paired " $\mathrm{t}$ " test was used to compare the means of bone fill within the groups at different time intervals. Independent " $\mathrm{t}$ " test for bone fill between the two groups at different time intervals.

The means and standard deviation of Plaque Index (PI), Sulcus bleeding index (SBI), probing depth (PD) and clinical attachment level (CAL) within sites of Smokers and Non-Smokers at different time intervals as shown in table 1 . When comparison of means of Plaque Index (PI), Sulcus Bleeding Index (SBI), Probing Depth (PD) and gain of Clinical attachment level (CAL) for both the smoker sites and Non-smoker sites after 6 months were done, there was a statistical significant difference was observed.

\section{Discussion}

Untreated periodontitis results in progressive attachment loss that may lead to early tooth loss. The tenacity of deep pockets succeeding after active periodontal therapy has been concomitant with an increased likelihood of tooth loss in patients attending the supportive periodontal care program.

Loss of alveolar bone support is one of the characteristic signs of destructive periodontal disease and is generally considered to represent the anatomical sequela to the spread of periodontitis [11], to overcome these problems surgical regenerative techniques were selected among them Single Flap.

Approach (SFA) was chosen treatment of choice in the present study. Single Flap Approach (SFA) exemplifies a surgical approach for the management of soft tissues in periodontal reconstructive surgery. SFA entails a mucoperiosteal flap elevated only on one side (buccal or oral), leaving the soft tissues on the opposite side intact. In the present study, only intraosseous defects with an extension prevalent on the buccal side were included.

The elevation of a single buccal flap to access the intraosseous defect may have several clinical and technical (surgical) advantages. First, it may facilitate flap repositioning and suturing. The buccal flap can be easily stabilized to the undetached oral papilla, thus optimizing wound closure for primary intention. Moreover, by leaving a great volume of supra crestal soft tissues intact, better preservation of the blood supply in the interdental area may eventually occur. Wound stabilization and preservation of an intact interdental papilla at the time of flap reflection may also contribute to better preservation of presurgical esthetics [12].

Numerous studies have testified considerable clinical improvements when SFA was used as a standalone protocol or in combination with recovering technologies for the treatment of deep periodontal intra osseous defects [13]. Intrabony defects have been categorized into three-wall, two-wall, one-wall defects.

Only three walled intrabony defects are included in the study because the number bony walls remaining has been found to be positively correlated with regeneration potential when grafting 
procedures were used [14]. A xenograft is tissue transported between genetically dissimilar members of different species. It is osteo-conductive, biocompatible and structurally similar to human bone. There are two sources of xenografts used for bone replacement in periodontics: bovine bone and natural coral. A purported advantage of this product as a bone substitute is that it is natural in that it can provide structural components similar to that of human bone, improving its osteoconductive capability compared to that of synthetically derived mineral Aichelmann-Reidy and Yukna [15].

Bovine derived HA bone substitutes increase the available surface area that can act as an osteoconductive scaffold because of their porosity. This HA mineral content is comparable to that of bone, allowing it to become well vascularized and integrate with new host bone (Thaller., et al. 1994; Chen., et al. 1996) [16,17]. A statistically significant gain of clinical attachment and reduction in probing depth has been demonstrated when bovine bone was compared to a non-graft control for the treatment of human vertical osseous defects. When compared to demineralized freeze-dried bone allograft (DFDBA), similar amounts of probing depth reduction, clinical attachment level gain, bone fill and defect resolution were obtained Richardson [18].

Hence in this present study an effort was made to evaluate the effect of TI-OSS ${ }^{\circledR}$ bovine xenograft in treatment of intrabony defects with single flap approach in smokers and non-smokers. The present study showed significant reduction in the means of Plaque index (PI), sulcus bleeding index (SBI), probing depth (PD) and gain of Clinical attachment level (CAL) for both the smoker sites and

Non-smoker sites after 6 months, but the mean reduction of PI, CAL and SBI between the sites showed no statistical significant association after 6 months. This denotes the application of Bovine Xenograft did not reveal any additional benefit in the reduction of PI, CAL and SBI. These results are concomitant the study of Trombelli [19]. This should be because of the regular and frequent recall visits in which the patients underwent regular supra-gingival scaling and motivation for oral hygiene practice, which further minimized plaque accumulation. This implied that the participants of the study exercised good oral home care.

Periodontal pocket is deliberated as the pathognomonic sign of periodontal disease and reduction in probing pocket depth is one of the requisites for successful periodontal therapy. Probing depth reduction in the present study was found to be significant from baseline to six months in the smokers' sites and Non-smoker sites.

Indicating that bovine xenograft has an added benefit on probing depth, this is similar to findings of a study of Yilmaz [20]. Tioss $^{\circledR}$ is prepared from $100 \%$ cancellous bone without any cortical portion. Innovative pulverizing technique allows multi-porous structure, maximizing blood vessel ingrowth, Pre-Hydroxy Apatite structure, octacalcium phosphate crystal is found on the surface of Ti-oss $^{\circledR}$, resulting in fast bone formation. In the present study bone gain was $30.73 \%$ in smoker group sites and $53.64 \%$ in Non-smoker group sites $(p=0.002)$. This attributed the placement of bovine xenograft with single flap approach which provides a significant postoperative protection from exfoliation of the graft from the surgical site. The obtained results are in accordance with study conducted by Tombelli [19].

The purpose of developing these new techniques is to increase predictability, reduce patient discomfort, minimize the number of surgical sites and satisfy aesthetic demands of the treatment. When comparing early wound healing index at 2 weeks after the surgery, smokers showed a significantly lower number of sites with optimal wound healing and a higher number of sites with incomplete flap closure when compared to nonsmokers ( $0 \%$ vs $45.5 \%$ and $45.5 \%$ vs $18.2 \%$, respectively), indicating a detrimental effect of smoking on early wound healing. This finding can be explained, at least in part by the alterations of the gingival vascular apparatus induced by the smoke $[21,22]$ which in turn may have impaired blood perfusion. Blood perfusion was demonstrated to be a key determinant of the early healing of muco-periosteal flaps, and its impairment is frequently associated with wound dehiscence [23].

Treatment with bovine xenograft using single flap approach at defects resulted in substantial clinical attachment gain, with no significant intergroup difference. The magnitude of treatment effect is consistent with previous clinical trials investigating the use of bovine xenograft in the treatment of intraosseous defects [24]. In standardized periodontal defects experimentally created in rat molars, Azuma., et al. [25] demonstrated that the elevation of a single flap. A lower number of neutrophils, more rapid colonization of the elevated gingival tissues by fibroblasts, and greater connective tissue area occupied by type III collagen during early postoperative healing when compared to wide double flaps [26]. 
Evaluation of Regenerative Periodontal Therapy in Intrabony Defects with Single Flap Approach Using Bovine Xenograft in Smokers and Non-smokers

Another explanation for the lack of effect of smoking status can be related to the inclusive definition of smoker patient adopted in this study. A patient who smoked at least 1 cigarette per day was considered a smoker. The inclusion of light smokers may have mitigated, at least in part, the negative effect of smoking on the clinical outcomes.

This hypothesis seems to be corroborated, where patients smoking more than 10 cigarettes per day showed a clear tendency toward a lower CAL gain and PD reduction compared to patients smoking 1 to 10 cigarettes per day. In the light of our results, it was stated that bovine xenograft has yielded significant reduction in probing depth, gain in clinical attachment level (CAL) and significant radiographic bone fill, showing superior effects in treatment of intraosseous defects in smokers and non-smokers.

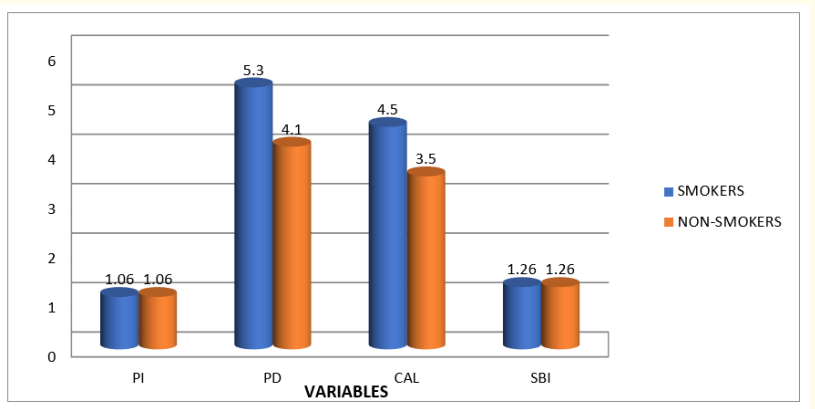

Graph 1: Comparison of mean difference of Plaque index (PI), Sulcus bleeding index (SBI), Probing depth (PD) and Clinical attachment level (CAL) between SMOKERS and NON-SMOKERS from baseline to 6 months.

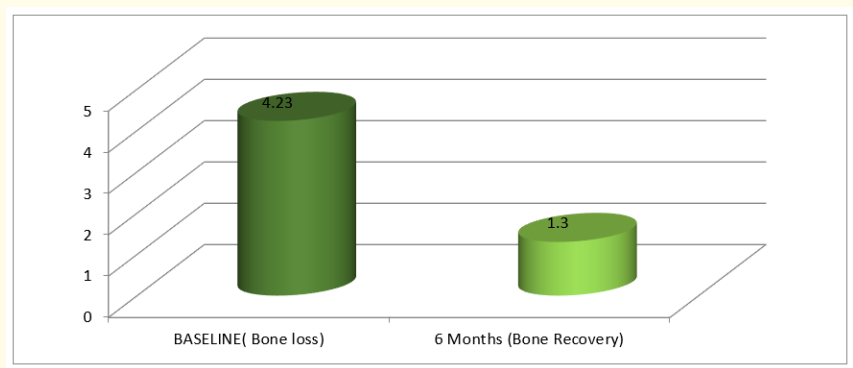

Graph 2: Comparison of means of bone gain in smokers from baseline to 6 months.

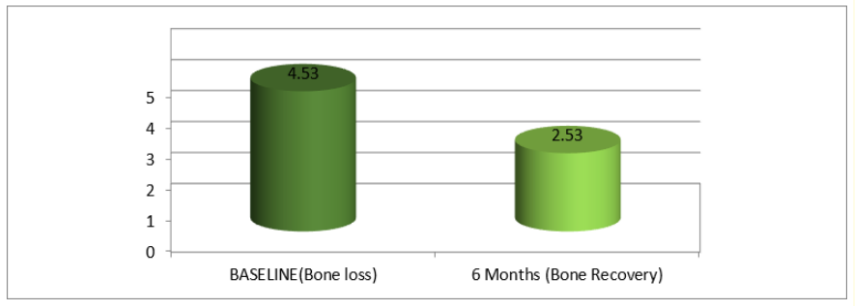

Graph 3: Comparison of means of bone gain in non-smokers from baseline to 6 months.

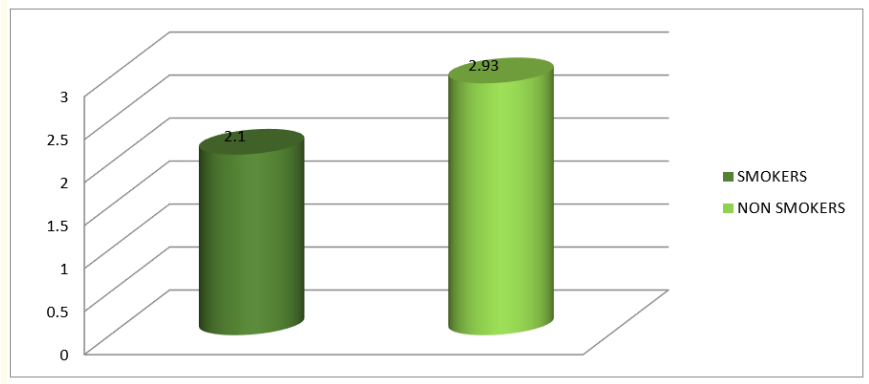

Graph 4: Comparison of Means difference of Bone gain between Smokers and Non-Smokers from Baseline to 6 Months.

\begin{tabular}{|l|c|c|c|}
\hline \multicolumn{1}{|c|}{ Variable } & Time interval & Smokers & Non-Smokers \\
\hline & & Mean \pm SD & Mean \pm SD \\
\hline Plaque index & Base line & $2.13 \pm 0.26$ & $2.15 \pm 0.26$ \\
\hline & 6 months & $1.14 \pm 0.22$ & $1.09 \pm 0.18$ \\
\hline Sulcus bleeding & Base line & $2.53 \pm 0.52$ & $2.53 \pm 0.52$ \\
\hline Index & 6 months & $1.47 \pm 0.52$ & $1.27 \pm 0.46$ \\
\hline Probing depth & Base line & $8.4 \pm 1.6$ & $7.7 \pm 1.2$ \\
\hline & 6 months & $3.1 \pm 0.5$ & $3.6 \pm 0.9$ \\
\hline Clinical & Base line & $10.0 \pm 1.9$ & $10.1 \pm 2.5$ \\
\hline Attachment & 6 months & $5.5 \pm 1.9$ & $6.5 \pm 2.0$ \\
level & & & \\
\hline
\end{tabular}

Table 1: Means and Standard Deviations of Plaque Index (PI), Sulcus Bleeding Index (SBI), Probing Depth (PD) and Clinical Attachment Level (CAL) In Smokers and Non-Smokers at Different Time Intervals. 
Evaluation of Regenerative Periodontal Therapy in Intrabony Defects with Single Flap Approach Using Bovine Xenograft in Smokers and Non-smokers

\begin{tabular}{|c|c|c|c|}
\hline Variable & Time interval & Smokers & Non-Smokers \\
\hline & & & \\
\hline Plaq & $\begin{array}{l}\text { Base line to } 6 \\
\text { months }\end{array}$ & $\begin{array}{l}1.06 \pm 0.08 \\
p=0.001(S)\end{array}$ & $\begin{array}{l}1.06 \pm 0.08 \\
\mathrm{p}=0.001(\mathrm{~S})\end{array}$ \\
\hline $\begin{array}{l}\text { Sulcus bleeding } \\
\text { index }\end{array}$ & $\begin{array}{r}\text { Base li } \\
\text { mor }\end{array}$ & $\begin{array}{l}1.26 \pm 0.06 \\
p=0.000(S)\end{array}$ & $\begin{array}{l}1.26 \pm 0.06 \\
p=0.000(S)\end{array}$ \\
\hline Prob & $\begin{array}{l}\text { Base line to } 6 \\
\text { months }\end{array}$ & $\begin{array}{c}5.3 \pm 1.3 \\
p=0.003(S)\end{array}$ & $\begin{array}{c}4.1 \pm 1.1 \\
p=0.003(S)\end{array}$ \\
\hline $\begin{array}{l}\text { Clinical } \\
\text { Attachment level }\end{array}$ & $\begin{array}{l}\text { Base line to } 6 \\
\text { months }\end{array}$ & $\begin{array}{c}4.5 \pm 1.9 \\
p=0.003(S)\end{array}$ & $\begin{array}{c}3.5 \pm 0.09 \\
p=0.003(S)\end{array}$ \\
\hline
\end{tabular}

Table 2: Comparison of Means of Plaque Index (PI), Sulcus Bleeding Index (SBI), Probing Depth (PD) and Clinical Attachment Level (CAL) in smokers and non-smokers within the sites from baseline to six months.

Statistical Analysis: Mann-Whitney U test. S: Significant. paired " $\mathrm{t}$ " test. Statistically significant if $\mathrm{p}<0.05$.

\begin{tabular}{|c|c|c|c|}
\hline Variable & Smokers & Non-Smokers & p VALUE \\
\hline & Mean \pm SD & Mean \pm SD & \\
\hline Plaque index & $1.06 \pm 0.08$ & $1.06 \pm 0.08$ & $\begin{array}{c}0.467 \\
\text { NS }\end{array}$ \\
\hline $\begin{array}{l}\text { Sulcus bleeding } \\
\text { index }\end{array}$ & $1.26 \pm 0.06$ & $1.26 \pm 0.06$ & $\begin{array}{c}0.148 \\
\text { NS }\end{array}$ \\
\hline Probing depth & $5.3 \pm 1.3$ & $4.1 \pm 1.1$ & $\begin{array}{c}0.028 \\
\mathrm{~S}\end{array}$ \\
\hline $\begin{array}{l}\text { Clinical } \\
\text { Attachment level }\end{array}$ & $4.5 \pm 1.9$ & $3.5 \pm 0.09$ & $\begin{array}{c}0.116 \\
\text { NS }\end{array}$ \\
\hline
\end{tabular}

Table 3: Comparison of mean difference of Plaque index (PI), Sulcus bleeding index (SBI), Probing depth (PD) and Clinical attachment level (CAL) between Smokers and Nonsmokers from baseline to 6 months.

Statistical Analysis: Independent ' $t$ ' test, paired t test. Statistically significant if $\mathrm{p}<0.05$.

NS: Non-significant.

S: Significant.

\begin{tabular}{|l|c|c|c|c|}
\hline & Smokers & $\begin{array}{c}\text { Non-smok- } \\
\text { ers }\end{array}$ & & \\
\hline $\begin{array}{c}\text { Time } \\
\text { interval }\end{array}$ & MEAN \pm SD & MEAN \pm SD & $\begin{array}{c}\text { \% of } \\
\text { recovery }\end{array}$ & p VALUE \\
\hline Base line & $4.23 \pm 0.94$ & $4.53 \pm 0.97$ & 53.64 & $0.000 \mathrm{~S}$ \\
\hline Six months & $1.30 \pm 0.47$ & $2.43 \pm 0.57$ & 30.73 & $0.000 \mathrm{~S}$ \\
\hline
\end{tabular}

Table 4: Comparison of Means and standard deviation of Bone Gain in Smokers and Nonsmokers From Baseline to 6months.

Statistical analysis: paired " $t$ " test. Statistically significant

$$
\text { if } \mathrm{p}<0.05 \text {. }
$$

\begin{tabular}{|l|c|c|c|}
\hline $\begin{array}{c}\text { Time } \\
\text { interval }\end{array}$ & Smokers & Non-smokers & P value \\
\hline & MEAN \pm SD & MEAN \pm SD & \\
\hline $\begin{array}{l}\text { Base line to } \\
6 \text { months }\end{array}$ & $2.10 \pm 0.40$ & $2.93 \pm 0.47$ & $0.002 \mathrm{~S}$ \\
\hline
\end{tabular}

Table 5: Comparison of Mean Difference of Bone Gain in Smokers and Non-Smokers from Baseline to Six Months.

Statistical analysis: independent sample ' $t$ ' test. Statistically significant if $\mathrm{p}<0.05$.

S: Significant.

\begin{tabular}{|l|c|c|}
\hline \multicolumn{1}{|c|}{ EHI score } & Smokers & $\begin{array}{c}\text { Non- } \\
\text { Smokers }\end{array}$ \\
\hline $\begin{array}{l}\text { Complete flap closure, no fibrin line in } \\
\text { the interproximal area }\end{array}$ & 3 & 5 \\
\hline $\begin{array}{l}\text { Complete flap closure, fine fibrin line in } \\
\text { the interproximal area }\end{array}$ & 3 & 4 \\
\hline $\begin{array}{l}\text { Complete flap closure, fibrin clot in the } \\
\text { interproximal area }\end{array}$ & 5 & 3 \\
\hline $\begin{array}{l}\text { Incomplete flap closure, partial } \\
\text { necrosis of the interproximal tissue }\end{array}$ & 0 & 0 \\
\hline $\begin{array}{l}\text { Incomplete flap closure, complete } \\
\text { necrosis of the interproximal tissue }\end{array}$ & 1 & 0 \\
\hline
\end{tabular}

Table 6: Early Healing Index (EHI) Assessment in smokers and non-smokers after 2 Weeks Following the Surgery.

\section{Conclusion}

We found that there was significant improvement in clinical parameters i.e., plaque index (PII), sulcus bleeding index (SBI), 
probing depth (PD), clinical attachment level (CAL), and bone fill in the sites, before and after periodontal treatment. There was a significant improvement in clinical attachment level gain and bone fill in both the groups treated with bovine xenograft using a single flap approach from baseline to six months. The results of this study point towards the novel direction of current surgical regenerative approaches. Further, long term, multi-center, prospective longitudinal trails are the need of the hour to confirm the finding of this study.

\section{Bibliography}

1. Dieter D., et al. "Does periodontal tissue regeneration really work". Periodontology 200051 (2009): 208-219.

2. Yilmaz S., et al. "Treatment of intrabony periodontal defects with platelet rich plasma versus platelet poor plasma combined with a bovine derived xenograft: A controlled clinical trial". Journal of Periodontology 82 (2011): 837-844.

3. Giannobile WV and Somerman SJ. "Growth and amelogenin like factors in periodontal wound healing. A systematic review". Annals of periodontology 8 (2003): 193-204.

4. Owes HR., et al. "Platelet derived growth factor enhances demineralized bone matrix- induced cartilage and bone formation". Calcified Tissue International 42 (1988): 34-38.

5. Choukroun J., et al. "Platelet rich fibrin (PRF): A second generation platelet concentrate. Part IV: Clinical effects on tissue healing". Oral Surgery, Oral Medicine, Oral Pathology, Oral Radiology, and Endodontology 101 (2006): E56-60.

6. Centrella M., et al. "Transforming growth factor- $\beta$ gene family members and bone”. Endocrine Review 15 (1994): 27-39.

7. Gunja C., et al. "A boon for periodontal regeneration". Journal of Advanced Research 4 (2006): 396-401.

8. Takei HH., et al. "Flap technique for periodontal bone implants. papilla preservation technique". Journal of Periodontology 56 (1985): 204-210.

9. Cortellini P., et al. "The modified papilla preservation technique. A new surgical approach for interproximal regenerative procedures". Journal of Periodontology 66 (1995): 261-266.
10. Palmer RM., et al. "Mechanisms of action of environmental factors-tobacco smoking". Journal of Clinical Periodontology 32 (2005): 180-195.

11. Papanou PN and Tonetti M. "Diagnosis and epidemiology of periodontal lesions”. Periodontology 200022 (2000): 8-21.

12. Trombellil L., et al. "Single flap approach with buccal access in periodontal reconstructive procedure". Journal of Periodontology 80 (2009): 353-360.

13. Farina R., et al. "Single flap approach in combination with enamel matrix derivative in the treatment of periodontal intraosseous defects". International Journal of Periodontics and Restorative Dentistry 34 (2014): 497-506.

14. Pradeep AR., et al. "Comparative evaluation of autologous platelet rich fibrin and platelet rich plasma in treatment of three walled intrabony defects in chronic periodontitis: A randomized controlled clinical trial". Journal of Periodontology 83 (2012): 1499-1507.

15. Aichelmann-Reidy ME and Yukna RA. "Bone replacement grafts, The bone substitutes". Dental Clinics of North America 42 (1998): 491-503.

16. Thaller SR., et al. "Repair of experimental calvarial defects with bio-oss particles and Collagen sponges in a rabbit model". Journal of Craniofacial Surgery 5 (1994): 242-246.

17. Chen L., et al. "Phenotypic catheterization of mononuclear cells following anorganic bovine bone implantation in rats". Journal of Periodontology 65 (1994): 1008-1015.

18. Richardson CR., et al. "Clinical evaluation of Bio-Oss: A bovinederived xenograft for the treatment of periodontal osseous defects in humans". Journal of Clinical Periodontology 26 (1999): 421-428.

19. Trombelli L., et al. "Regenerative periodontal treatment with the single flap approach in smokers and smokers". International Journal of Periodontics and Restorative Dentistry 38 (2018): e59-e67.

20. Yilmaz S., et al. "Regenerative treatment with platelet-rich plasma combined with a bovine-derived xenograft in smokers 
and non-smokers:12-month clinical and radiographic results".

Journal of Clinical Periodontology 37 (2010): 80-87.

21. Johnson GK and Guthmiller JM. "The impact of cigarette smoking on periodontal disease and treatment". Periodontology 200044 (2007): 178-194.

22. Palmer RM., et al. "Mechanisms of action of environmental factors-Tobacco smoking". Journal of Clinical Periodontology 32 (2005): s180-s195.

23. Zanetta-Barbosa D., et al. "Laser Doppler flowmetry of blood perfusion in mucoperiosteal flaps covering membranes in bone augmentation and implant procedures. A pilot study in dogs". Clinical Oral Implants Research 4 (1993): 35-38.

24. Palachur D., et al. "A comparative evaluation of bovine-derived xenograft (bio-oss collagen) and type I collagen membrane (bio-gide) with bovine-derived xenograft (bio-oss Collagen) and fibrin fibronectin sealing system (tisseel) in the treatment of intrabony defects: A clinicoradio graphic study". Journal of Indian Society of Periodontology 18 (2014): 336-343.

25. Azuma H., et al. "Single flap periodontal surgery induces early fibrous tissue generation by wound stabilization". Journal of Hard Tissue Biology 26 (2017): 119-126.

26. Wennström JL and Lindhe J. "Some effects of enamel matrix proteins on wound healing in the dento-gingival region". Journal of Clinical Periodontology 29 (2002): 9-14.

\section{Assets from publication with us}

- Prompt Acknowledgement after receiving the article

- Thorough Double blinded peer review

- Rapid Publication

- Issue of Publication Certificate

- High visibility of your Published work

Website: www.actascientific.com/

Submit Article: www.actascientific.com/submission.php

Email us: editor@actascientific.com

Contact us: +91 9182824667

Citation: Dalli Bharath Simha Reddy., et al. "Evaluation of Regenerative Periodontal Therapy in Intrabony Defects with Single Flap Approach Using Bovine Xenograft in Smokers and Non-smokers". Acta Scientific Dental Sciences 5.4 (2021): 40-48. 